\title{
Leaf thickness to predict plant water status
}

Amin Afzal ${ }^{1, *}$, Sjoerd W. Duiker ${ }^{2}$, John E. Watson ${ }^{3}$

${ }^{1}$ Department of Plant Science, 116 ASI Building, The Pennsylvania State University, University Park, PA 16802, United States, email: sua180@psu.edu

${ }^{2}$ Department of Plant Science, 116 ASI Building, The Pennsylvania State University, University Park, PA 16802, United States, email: sduiker @ psu.edu

${ }^{3}$ Department of Ecosystem Science and Management, 116 ASI Building, The Pennsylvania State University, University Park, PA 16802, United States, email: jackwatson@ psu.edu

* Correspondence: +1-814-470-6698 


\section{Leaf thickness to predict plant water status}

\section{Abstract}

3 Plant-based techniques to measure crop water status offer advantages over soil-based methods.

4 The objective of this study was to quantify the relationship between leaf thickness

5 measurements, as a promising plant-based technique, with leaf relative water content (RWC) and

6 assess the model across different species and leaf positions. The relationship between RWC and

7 relative thickness (RT) was determined on corn (Zea mays L.), sorghum (Sorghum bicolor (L.)

8 Moench), soybean (Glycine max (L.) Merr.), and fava bean (Vicia faba L.). RWC was calculated

9 as measured leaf water content/leaf water content at full turgor, and RT as measured leaf

10 thickness/leaf thickness at full turgor. Two leaves from the top, middle, and bottom of five plants

11 of each species were collected at 60 days of age. Leaf samples brought to full turgor were left to

12 dehydrate in a lab. Leaf thickness was measured using a magnetic field sensor and water content

13 using weight loss. The RWC-RT relationship showed a distinct breakpoint, which we

14 hypothesize coincides with the turgor loss point. Linear piecewise modelling was used to regress

15 RWC versus RT, resulted in models explaining 86-97\% of the variations. The precision was

16 improved by including leaf position on the plant in the model. The piecewise model parameters

17 were related to salt tolerance of the species, which is also an indicator of drought resistance.

18 Generally, the species with greater drought and salinity tolerance had a larger RT at the

19 breakpoint.

Keywords: leaf thickness sensor; water stress; plant water status; drought tolerance; leaf 


\section{Symbols and abbreviations}

\section{Nomenclature}

a The intercept of the piecewise linear model of leaf relative water content versus leaf relative thickness for where relative thickness is equal or smaller than the breakpoint

$b_{1} \quad$ The slope of the piecewise linear model of leaf relative water content versus leaf relative thickness for where relative thickness is greater than the breakpoint

$b_{2} \quad$ The slope of the piecewise linear model of leaf relative water content versus leaf relative thickness for where relative thickness is equal or smaller than the breakpoint

c The leaf relative thickness at the breakpoint of the piecewise linear model of leaf relative water content versus leaf relative thickness

EC Soil electrical conductivity

TLP Turgor loss point

RT Leaf relative thickness

RWC Leaf relative water content

\section{1. Introduction}

5 Improvements in water use efficiency can be achieved by precision irrigation timing to avoid

6 early or late irrigation, which may lead to water or yield loss. Ideally continuous measurements

7 of plant water status would be the optimum means to determine the best irrigation timing.

8 Common methods of plant water status estimation for practical applications tend to range from

9 the simple visual wilting approach to measurement intensive evapotranspiration models, or soil

10 moisture measurements (Jones, 2004). Irrigation scheduling based on plant measurements merits

11 consideration as an alternative to soil measurements and/or water balance computations. There

12 are plant-based alternatives for estimating plant water needs, such as pressure chamber,

13 psychrometer, thermal sensing, and sap-flow sensors (Jones, 2004). We propose a simple

14 measurement method based on leaf thickness as suggested by Seelig, Stoner, and Linden (2011). 
Instead of improving soil moisture measurement methods or evapotranspiration models, we suggest it may be better if the critical water stress points at which irrigation should start could be directly measured on the crops grown. Plant-based approaches may offer a more reliable plant water status estimation by reducing the need for complex calculations and data sets associated with soil-plant-atmosphere water relationship (Jones, 2004; Kramer \& Boyer, 1995). In this study, we set out to determine if leaf thickness could be a reliable indicator of water status of a plant.

Bachmann (1922) was the first to report that leaf thickness decreases upon dehydration and increases upon rehydration. Subsequently, Meidner (1952) determined that there is a strong correlation between leaf thickness and relative water content (RWC). Búrquez (1987) reported a strong correlation between RWC and leaf thickness in Brassica napus L., Mirabilis jalapa L., Phaseolus vulgaris L., and Impatiens parviflora DC. These researchers measured leaf thickness using different types of calipers and micrometers. Meidner (1952) used a gear-wheel micrometer and Búrquez (1987) used a spring-loaded gear-wheel. These devices were bulky and hard to automate to enable continuous plant water stress sensing. Transducer-based techniques were explored to enable automated leaf thickness measurement (Dongsheng, Manxi, Huijuan, \& Ziqian, 2007; Li \& Song, 2009; Malone, 1993; Marenco, Antezana-Vera, \& Nascimento, 2009; McBurney, 1992; Rozema, Arp, Diggelen, Kok, \& Letschert, 1987; Syvertsen \& Levy, 1982; Vile et al., 2005; White \& Montes-R, 2005). Most of these sensors are relatively bulky linear variable displacement transducers (LVDT).

Sharon and Bravdo (1996) and Seelig et al. (2011) developed tiny leaf thickness sensors to optimize irrigation scheduling. Sharon and Bravdo (1996) compared irrigation scheduling using continuous leaf thickness monitoring with four conventional drip irrigation regimes based on timetables and water depletion. In this 4-year study, the sensor-based drip irrigation treatment resulted in the highest yield and greatest water use efficiency of grapefruit cv. Oroblanco (Citrus $x$ paradisi Macfad). Similarly, Seelig et al. (2011) were able to improve water use efficiency of irrigated cowpea 25 to $45 \%$ by an automated irrigation system based on a leaf thickness sensor compared with timed irrigation scheduling. These studies show that irrigation scheduling based on the automated leaf thickness sensing has the potential to improve water use efficiency and conserve irrigation water. 
The relationship between leaf thickness and RWC depends on plant and leaf characteristics and

2 is affected by environmental variables. Leaf thickness is determined by plant anatomy, including the number, size, and arrangement of leaf cells that differ among species (Carpenter \& Smith, 1979; Nicotra et al., 2011; Taiz \& Zeiger, 2006; Vogelmann, Bornman, \& Yates, 1996). Giuliani et al. (2013) have reported a significant difference in leaf anatomy among species of the genus Oryza. There is a significant variation in the structure of leaf mesophyll even between leaves

located at different positions on the same plant (Eames \& MacDaniels, 1925). The number and arrangement of the palisade parenchyma, as well as the overall morphology of a leaf, vary between species. They also depend on environmental variables such as light exposure, temperature, age, and irrigation regimes (Abrams \& Kubiske, 1990; Búrquez, 1987; Carpenter \& Smith, 1979; Gausman, Allen, Cardenas, \& Richardson, 1970; Gausman, 1974; Hanba, Miyazawa, \& Terashima, 1999; Nicotra et al., 2011; Taiz \& Zeiger, 2006).

Leaf thickness changes not only as a result of RWC fluctuations but also due to environmental and physiological factors (Blum, 2011; Scoffoni, Vuong, Diep, Cochard, \& Sack, 2014; Taiz \& Zeiger, 2006). Some of these are rapid. For example, leaf thickness shows a diurnal-nocturnal dynamic. Under well-hydrated conditions, leaf thickness is almost constant during night hours but decreases during the day (Búrquez, 1987; Meidner, 1952; Rozema et al., 1987; Seelig et al., 2011; Syvertsen \& Levy, 1982). Leaf thickness was negatively correlated with air temperature and light and positively with ambient relative humidity (Búrquez, 1987; Rozema et al., 1987; Syvertsen \& Levy, 1982). These environmental factors affect leaf thickness variations through their role in transpiration (Búrquez, 1987; Giuliani et al., 2013; Rozema et al., 1987). Vapour loss and water supply as the discharge and charge sources of the leaf water content result in varying leaf thickness (Búrquez, 1987). Soil salinity increases leaf shrinkage during the day and the time of thickness recovery at night (Rozema et al., 1987). This may be explained by the water shortage-induced condition which causes plants to reduce water uptake from a saline medium (Blum, 2011; Parida \& Das, 2005; Rozema et al., 1987). On the other hand, wounding, for example by insects, causes rapid leaf swelling (Alarcon \& Malone, 1994).

Leaf thickness has been shown to affect photosynthesis (Smith, Bell, \& Shepherd, 1998; Taiz \& Zeiger, 2006). Varieties with thicker leaves show enhanced photosynthesis, a character trait used by plant breeders to improve yields (Peng \& Ismail, 2004; Takai et al., 2013). Physiological 
changes that affect leaf thickness can have a long-lasting effect. Smith et al. (1998) found that a decrease in precipitation and an increase in leaf inclination were associated with thicker leaves. In addition, there is a positive correlation between leaf thickness and total daily light exposure (Abrams \& Kubiske, 1990; Carpenter \& Smith, 1981; Eames \& MacDaniels, 1925; Nobel \& Hartsock, 1981; Smith et al., 1998; Yun \& Taylor, 1986). Nobel and Hartsock (1981) reported a positive correlation between leaf thickness and leaf age.

A number of researchers have worked on the relationship between leaf thickness and leaf structural and functional traits (Giuliani et al., 2013; Patakas \& Noitsakis, 1997; Sack \& Scoffoni, 2012; Scoffoni et al., 2014). Leaf thickness was positively correlated with leaf hydraulic conductivity (Scoffoni et al., 2014) and elastic modulus (Aasamaa, Niinemets, \& Sõber, 2005; Scoffoni et al., 2014). Drought results in cell wall hardening and larger elastic modulus which helps the tissue maintain turgor pressure and avoid water stress (Blum, 2011; Martinez, Silva, Ledent, \& Pinto, 2007). Salinity decreased the epidermal and mesophyll thickness of mangrove B. parviflora leaves (Parida, Das, \& Mittra, 2004). The tight relationship between leaf thickness and leaf water potential $\left(\psi_{\text {leaf }}\right)$ was shown in several studies (Búrquez, 1987; McBurney, 1992; Neumann, Thurtell, Stevenson, \& Beadle, 1974; Scoffoni et al., 2014; Syvertsen \& Levy, 1982).

In summary, earlier work suggests leaf thickness measurement to be a feasible technique for estimation of plant water status. However, the earlier studies did not quantify the relationship between leaf thickness and RWC, which is often employed as a measure of plant water condition (Jones, 2007; Seelig, Wolter, \& Schröder, 2015). In spite of this, Jones (2007) recommended use of RWC as a measure of plant water status for irrigation scheduling purposes. In practical applications (e.g. irrigation timing), using leaf thickness measurements as a means for estimation of plant water status requires a quantified relationship to determine when to irrigate.

In addition, as mentioned earlier, leaf thickness is a function of leaf structural traits which may vary by species and leaf position on the plant. Therefore, another question is whether species and leaf position on the plant influence the leaf thickness - leaf water content relationship.

Therefore, the objective of this study was to determine the relationship between RWC and leaf relative thickness (RT). The species were selected from dicotyledons and monocotyledons with 
1 different drought tolerances to study their differences in the RWC-RT relationship. This study

2 also considered the extent to which leaf location on a plant impacted the relationship.

\section{2. Materials and methods}

\section{$4 \quad$ 2.1. Plant cultivation}

5 Corn (Zea mays L., hybrid DKC53-45), sorghum (Sorghum bicolor (L.) Moench, cv. AF7101),

6 soybean (Glycine $\max ($ L.) Merr., cv. HS 2766), and fava bean (Vicia faba L., cv. Vroma) were

7 grown under controlled conditions in a greenhouse at the Pennsylvania State University,

8 University Park, Pennsylvania. Fifteen plants of each crop were grown in eight-litre pots filled

9 with a loamy soil, under a mixture of natural and artificial light to generate a photoperiod of 15

10 hours, day/night temperatures of $27 / 18^{\circ} \mathrm{C}$, relative humidity of $60 \%( \pm 20 \%)$, and were irrigated

11 every three days to maintain field capacity - a set of environmental conditions favourable for all

12 the crops grown to provide non-stress growing conditions. No fertilizer or pesticide was applied.

13 2.2. Leaf sampling

14 Sixty days after seeding, the pots were irrigated to saturation eight hours before collecting the

15 leaves. Two leaves were selected from top, middle and bottom of five randomly selected plants of each species (five replications). The petioles of the cut leaves were immediately submerged in

17 distilled water and the entire leaves and the container holding the water were enclosed in dark

18 polyethylene bags. These bags were stored in the dark at $7^{\circ} \mathrm{C}$ for eight hours in a refrigerator to ensure that leaves reached full turgidity (Búrquez, 1987).

20 Two $225 \mathrm{~mm}^{2}$ samples were taken from the centre of a leaf (avoiding the edges and major veins)

21 under lab conditions $\left(25^{\circ} \mathrm{C}\right.$ and relative humidity of $\left.40 \pm 5 \%\right)$. One sample was used for

22 continuous leaf thickness measurement and the other sample was used for continuous leaf

23 weighing. This method was chosen because it was not possible to simultaneously weigh the

24 sample with the sensor attached to it due to wiring attaching the sensor to the data logger. In

25 addition, the aim was to not remove the leaf thickness sensor to prevent possible leaf damage,

26 loss of data continuity, and spikes or drops in thickness measured due to repositioning the sensor.

27 The preliminary data confirmed the made assumption for this method that the rate of water loss 
over time was not significantly different for two leaf pieces dehydrating under the same conditions in the lab.

\subsection{Leaf thickness and water content measurement}

Leaf thickness was measured by a developed leaf thickness sensor using a magnetic field sensor and two permanent magnets that were fixed on a clear rigid clip (Fig. 1). One of the magnets and the magnetic field sensor were fixed on opposite sides of the clip. The voltage output of the magnetic field sensor varied based on the distance from this magnet enabling continuous leaf thickness measurement. The second magnet was fixed under the magnetic field sensor with the opposite polarity to the other magnet to reduce the offset magnetic field. This magnet helps to avoid sensor saturation for very small thicknesses while still allowing high resolution. Sensor calibration using paper sheets of known thickness showed a coefficient of determination of 0.99 with an accuracy of $4 \mu \mathrm{m}$ and a precision of better than $1 \mu \mathrm{m}$. Sensor output was recorded at one-minute intervals using a DT85M data logger (DataTaker, Melbourne, Australia).

RWC was calculated as follows:

$$
\text { RWC }=100 \times \frac{\text { actual leaf weight }- \text { dry weight }}{\text { turgid leaf weight }- \text { dry weight }}
$$

where actual leaf weight is the weight of the sample placed on the balance, turgid leaf weight is the weight of the leaf sample at full turgor, and dry weight is the weight of the leaf sample dried in an oven at $60{ }^{\circ} \mathrm{C}$ for 24 hours.

At the start of a measurement period, two pieces were taken from a leaf: one piece was inserted in the thickness sensor for leaf thickness measurement and the other piece was put on a balance for weighing under the same environmental conditions.

The samples for RWC measurements were weighed every 5 minutes from full turgidity to $60 \%$ RWC. Since the time interval between RWC measurements was greater than that between leaf thickness measurements, the missing RWC data were calculated by linear interpolation. The result was one-by-one RWC and leaf thickness data at intervals of 1 minute.

Leaf thickness among leaves varied and therefore RT was used, which was calculated as follows: 


\section{2.4. Statistical analysis}

3 Minitab 16.0 was employed for ANOVA while the nonlinear procedure of SAS 9.3 was used for

4 piecewise linear regression of RWC-RT as described by Ryan and Porth (2007). The following

5 equation shows the applied piecewise parametric model utilized to represent the RWC-RT

6 relationship:

$$
\mathrm{RWC}=\left\{\begin{array}{rrr}
a+c\left(b_{2}-b_{1}\right)+b_{1} \mathrm{RT}, & \mathrm{RT}>c & \text { (phase } 1) \\
a+b_{2} \mathrm{RT}, & \mathrm{RT} \leq c & \text { (phase } 2)
\end{array}\right.
$$

where $a$ is the intercept with the y-axis (RWC) of the regression line below the breakpoint, $c$ is the RT at the breakpoint, $b_{1}$ is the slope of the line at $\mathrm{RT}>c$, and $b_{2}$ is the slope of the line at $\mathrm{RT} \leq c$. Parameter estimates are shown in Tables 1 and 2.

\section{Results and discussion}

\subsection{RWC-RT relationship}

The RWC-RT relationship of each species averaged by leaf location is shown in Fig. 2. The RWC-RT curve showed a sudden change in slope at a point we refer to as the "breakpoint". To reflect this non-linear behaviour and the distinct breakpoint, piecewise linear regression modelling was used to regress RWC vs. RT (equation 3).

The slope of the regression line at the early stages of dehydration was much larger than the slope of the line at the later stages of dehydration (Fig. 2). This means that RT changed much with a given change in RWC at early stages of dehydration, while RT changed little with a given change in RWC at later stages of dehydration. This result is in agreement with the results of Sancho-Knapik, Alvarez-Arenas, Peguero-Pina, Fernández, and Gil-Pelegrín (2011) on Quercus muehlenbergii Engelm. They reported that a breakpoint occurred at the turgor loss point (TLP) in the relationship of RWC and leaf thickness such that the changes of RWC for a given decrement in leaf thickness from full turgor to TLP was small in comparison with that below TLP. TLP can be considered as a critical water stress since it represents the point that leaf turgor pressure is equal to zero bar and the tissue transitions from a turgid to a flaccid state (Taiz \& Zeiger, 2006). 
This breakpoint has also been observed in the relationship between RT and leaf water potential

2 in other studies (Begg et al., 1964; Lenz, Wright, \& Westoby, 2006; Neumann et al., 1974;

3 Sanchez-Diaz \& Kramer, 1971; Scoffoni et al., 2014; Stoyanov, 2005). Neumann et. al. (1974)

4 and Scoffoni et. al. (2014) reported a distinct breakpoint in the dynamics of leaf thickness versus

$5 \quad \psi_{\text {leaf }}$ which occurred at TLP. These results imply that the observed breakpoint in our study

6 occurred at TLP and represents a critical water status threshold.

7 Seelig et al. (2015) stated that the leaf thickness seems to change more rapidly compared to 8 RWC in the early stage of leaf dehydration, similar to the observed contrast between the early 9 and late slopes of the RWC-RT relationship in the leaf dehydration process in our study. In an 10 effort to explain such a behaviour by a physiological property, they hypnotized that leaf 11 thickness is related to turgor pressure of leaf cells. They investigated this relationship using bean 12 plants (Phaseolus vulgaris L.). They observed strong correlations between leaf thickness and leaf water potential for each individual leaf. However, they could not find a general relationship

14 between leaf thickness and either leaf turgor potential or leaf water potential. However, they reported that this result could be caused by errors in their method for estimating leaf turgor potential.

17 McBurney (1992) observed a strong non-linear relationship between leaf water potential and leaf thickness of Brussels sprout plants (Brassica oleracea var. gemmifera D.C. cv. Gabion). However, the pattern of this relationship varied across the leaves of different plants such that the results did not allow them to draw a general relationship between leaf water potential and leaf thickness of Brussels sprout plants.

22 In contrast, our data (Fig. 2) shows that the relationship between RWC and RT followed a 23 consistent non-linear pattern that could be explained by a piecewise linear model.

\section{3.2. Estimated model parameters by species}

25 Table 1 shows the estimated model parameters for each species, averaged over the leaf locations. 26 Large differences were observed among the estimated model parameters of the species. The 27 slope of the regression line in phase $1\left(b_{1}\right)$ was greatest for sorghum, followed by soybean, fava 28 bean and smallest for corn. In phase 1, in sorghum, RT changed least with a given change of 29 RWC, while it changed most with a unit change of RWC in corn. The slope $b_{1}$ of soybean was 
similar to that of sorghum while $b_{1}$ of fava bean was similar to that in corn. The breakpoint $c$ occurred at the largest RT in sorghum, followed by corn, soybean, and fava bean. The slope of the line in phase $2\left(b_{2}\right)$ was largest for sorghum, followed by corn, soybean, and smallest for fava bean.

The results show that the relationship between RWC-RT varied by species. The relationship may also vary across different varieties of a species. This question requires further examination.

The dynamics of the RWC-RT relationship can possibly provide information about species' drought tolerance. The greatest differences between the estimated slopes and breakpoint occurred between sorghum and fava bean. Sorghum had the greatest slopes in both phases and the highest RT at the breakpoint $c$. Fava bean, on the other hand, had the smallest $b_{2}$, the smallest $c$, and the second smallest $b_{1}$. Sorghum is among the most drought tolerant cultivated crops (Sabadin et al., 2012). Fava bean, on the other hand, is known for its lack of drought tolerance (Multari, Stewart, \& Russell, 2015). Therefore, this suggests that a drought-sensitive crop might have a smaller $c$ while a drought-tolerant species would have a larger $c$. This interpretation implies that the drought tolerance of corn and soybean is intermediate between sorghum and fava bean.

Blum (2011), Giuliani et al. (2013), and Patakas and Noitsakis (1997) have recognized that there is a relationship between cell rigidity and drought tolerance by maintaining cell structure at lower water potentials. A larger RT at the breakpoint suggests that the leaves transitioned from an elastic to a more rigid behaviour sooner, exhibiting an overall more rigid behaviour throughout the dehydration process. This implies that RT at the breakpoint is related to the crop drought tolerance. These interpretations are in agreement with Scoffoni et al. (2014) who reported that the thickness of leaves of moist habitat species decreased more from full-turgor to TLP (breakpoint) compared with the leaves of dry habitat species better adapted to drought.

\subsection{Monocotyledons versus dicotyledons}

RT at the breakpoint $c$ and the slope $b_{2}$ were larger for the monocot (monocotyledon) species than for the dicot (dicotyledon) species, implying that the leaves of monocots had overall less elastic behaviours. These differences are in agreement with the leaf anatomical differences, specifically bulk leaf rigidity, between monocots and dicots. 
1 In contrast to the dicots, the monocot leaves contain dense longitudinal main veins and silica 2 deposition providing mechanical strength to their long leaves (Read \& Stokes, 2006). Thicker 3 cell walls, greater lignin content in the vascular tissues (Myburg \& Sederoff, 2001; Sack \& 4 Scoffoni, 2013) and higher silica content (Read \& Stokes, 2006), result in a more rigid bulk leaf 5 blade in the monocots than in dicots. Therefore, the larger $c$ and $b_{2}$ for the monocot leaves may be explained by the more rigid leaf structure of these species compared to that of dicots.

\section{7}

\subsection{RWC-RT model and salt tolerance}

Salt tolerance of a species is characterized by a threshold EC (soil electrical conductivity) below which crop yield is not affected (Hoffman, Rhoades, Letey, \& Sheng, 1990; Maas \& Hoffman, 1977). Since drought and salt tolerance mechanisms of plants are closely related (Jones, 2014; Kramer \& Boyer, 1995; Taiz \& Zeiger, 2006), the relationship between threshold EC levels for the crops and model parameters were investigated.

The slope $b_{1}$ was strongly correlated with the salinity thresholds (Fig. 3A). Also, the crops with higher thresholds tended to have greater RT values at the breakpoint $c$, and greater $b_{2}$ slopes (Fig. 3B and Fig. 3C). These results suggest that larger $b_{1}, b_{2}$, and $c$ may be indicators of a more salttolerant crop.

Cell wall rigidity is one of the salt-tolerance mechanisms of crops to maintain cell structure at low water potentials (Gall et al., 2015; Morgan, 1986; Zagorchev, Kamenova, \& Odjakova, 2014). Therefore, if a larger breakpoint and smaller rates of RT variations in response to dehydration (larger $b_{1}$, and $b_{2}$ ) imply a more rigid structure, the effect of cell wall rigidity may explain the positive correlation between the piecewise parameters and the salinity threshold.

Salinity reduces soil water osmotic potential which impedes water uptake, increasing drought stress (Taiz \& Zeiger, 2006). Crops share some similar tolerance mechanisms for salt and drought stresses (Jones, 2014; Kramer \& Boyer, 1995; Taiz \& Zeiger, 2006). These results suggest that a larger breakpoint $c$ and larger slopes $b_{1}$ and $b_{2}$ might reflect a greater salt tolerance and accordingly, a greater drought tolerance of a crop. 
3.5. Effect of leaf location on the RWC-RT relationship

2 Table 2 shows the estimated piecewise parameters for different leaf locations by the species.

3 Leaf location had a significant effect on most parameters of the RWC vs. RT relationship of all

4 four species (Table 3). Leaf location significantly affected $b_{1}$ for all the species, the breakpoint $c$

5 for corn and sorghum, and $b_{2}$ and $a$ for soybean and fava bean. McBurney (1992) also observed

6 that the slope of the leaf thickness vs. leaf water potential for higher position leaves differed

7 from that of lower position leaves in Brussels sprout plants.

8 Evidently, the effects of leaf position on model parameters varied by species. Leaf position

9 reflects leaf age and light exposure which affect leaf structural traits. Sylvester (2001) reported a

10 significant effect of age on the leaf anatomy of corn, rice, and bluegrass. Aging causes cell wall

11 thickening and increased elastic modulus (Lambers, Chapin, \& Pons, 2008; Patakas \& Noitsakis,

12 1997). The penetration of sunlight decreases from top to bottom of a canopy (Jones, 2014). In

13 our study, the plants were spaced sufficiently close together such that upper leaves shaded lower

14 leaves. Exposure to sunlight has a strong influence on the leaf structure (Smith et al., 1998).

15 Vogelmann et al. (1996) showed that sun-leaves (leaves directly exposed to sunlight) of

16 Thermopsis montana had longer palisade cells and were much thicker than shade-leaves (leaves

17 that do not receive direct sunlight). The cell walls of sun-leaves have higher lignin content and greater rigidity than shade-leaves (Gall et al., 2015).

The breakpoint $c$ of monocots was smaller for the top leaves than for the bottom leaves while this trend was reversed for the dicots. The growth pattern of monocots implies that the older leaves are at the bottom while younger leaves are at the top. Since age affects cell wall rigidity (Nobel, 2009; Patakas \& Noitsakis, 1997), the lower leaves of the monocots are expected to have more rigid bulk structure than the higher leaves. This rigidity may help explain why lower leaves of the monocots had a larger c. McBurney (1992) observed that the hardened leaf cells of 25 droughted plants shrank more lateraly and less longitudinally (in the direction of the leaf thickness) compared to the non-hardedned leaf cells of non-droughted plants, suggesting that the

27 hardened cells had more longitudinal rigidity.

On the other hand, the growth pattern of dicot species does not ensure the vertical age 29 distribution of leaves. The plant grows vertically along the main stem and laterally by branching. Therefore, in dicots, the leaf location does not assure the order of leaf age along the main stem. 
1 However, for the dicots, the leaf location may reflect the light distribution. Light exposure of

2 leaves of monocot species at lower levels in the canopy may not decrease as much as in dicots

3 because the helical leaf arrangement and a smaller horizontal leaf angle allow more light

4 penetration in monocots (Read \& Stokes, 2006). It is known that the cell wall lignin content and

5 the bulk elastic modulus of sun-leaves are greater than shade-leaves (Gall et al., 2015).

6 Therefore, it appears that the leaves near the top of the dicots received more light and therefore

7 had more rigid cells, resulting in more tissue rigidity and larger $c$ values.

8 4. Conclusion

9 This study shows that leaf thickness can be used to measure leaf relative water content. We observed an abrupt increase of the slope of the RWC-RT curve as leaves dried out. Piecewise linear regression resulted in models that explained $86-97 \%$ of the variation of RWC-RT relationship of the four species studied. We suggest that the parameter $c$ in these models represents the RT at the TLP. The relationship between RT and RWC varied by species and leaf location. To use leaf thickness as an estimate of leaf water content, it is, therefore, necessary to develop models that vary by species, leaf location, and probably variety.

It is recognized that model calibrations will change as leaves age - a top leaf may become a 17 middle leaf later. Additionally, environmental factors such as light, temperature, relative humidity, disease, and pest pressure may affect leaf thickness as well. We recognize that the results were impacted by growing the plants in pots in a greenhouse rather than in a field. Some of these differences may include root distribution, nutrient availability, and variability of the soil structure that may affect plant water uptake, growth characteristics, and leaf physiological and anatomical structure, which may impact the leaf thickness and water content relationship.

Additional work building on this research accounting for some of these environmental factors would strengthen the development of more reliable models. We suggest that the RWC-RT curves 25 can provide information about drought and salt tolerance of species. If it is true that the breakpoint $c$ represents TLP, the breakpoint implies a critical water stress level which leads to a 27 dramatic change in the leaf physiology. This information could be used to screen species and 28 varieties for drought and salinity tolerance. In addition, this knowledge may be applied to develop leaf thickness sensors to monitor plant water stress for irrigation scheduling and drought 
1 monitoring. Since plant water potential is widely adopted as an indicator of plant water

2 condition, further work to determine a relationship between leaf thickness and leaf water

3 potential components may help develop a better understanding of the relationship between leaf

4 thickness variations and plant water status.

\section{Acknowledgment}

6 The authors acknowledge the support of the greenhouse manager at the Pennsylvania State

7 University, Scott Diloreto, for his help during the crop growth period in the greenhouse. We

8 appreciate the guidance of Dr. Dawn Luthe and Dr. Paul Heinemann. This work was supported

9 by the United States Department of Agriculture (USDA) National Institute of Food and

10 Agriculture, Hatch project 4425. Any opinions, findings, conclusions, or recommendations

11 expressed in this publication are those of the authors and do not necessarily reflect the view of

12 the National Institute of Food and Agriculture (NIFA) or USDA.

\section{References}

Aasamaa, K., Niinemets, U., \& Sõber, A. (2005). Leaf hydraulic conductance in relation to anatomical and functional traits during Populus tremula leaf ontogeny. Tree Physiology, 25, 1409-1418.

Abrams, M., \& Kubiske, M. (1990). Leaf structural characteristics of 31 hardwood and conifer tree species in central Wisconsin: influence of light regime and shade-tolerance rank. Forest Ecology and Management, 31, 245-253.

Alarcon, J., \& Malone, M. (1994). Substantial hydraulic signals are triggered by leaf-biting insects in tomato. Journal of Experimental Botany, 45(276), 953-957.

Bachmann, F. (1922). Studien über die dickenänderung von laubblättern. Jahrbücher Für Wissenschaftliche Botanik, 61, 372-429.

Begg, J. E., Bierhuizen, J. F., Lemon, E. R., Misra, D. K., Slatyer, R. O., \& Stern, W. R. (1964). Diurnal energy and water exchanges in bulrush millet in an area of high solar radiation. Agricultural Meteorology, 1(4), 294-312.

Blum, A. (2011). Plant water relations, plant stress and plant production. Plant breeding for water-limited environments (pp. 11-52). New York, NY: Springer New York. 
Búrquez, A. (1987). Leaf thickness and water deficit in plants: a tool for field studies. Journal of Experimental Botany, 38(186), 109-114.

Carpenter, S. B., \& Smith, N. D. (1979). Variation in shade leaf thickness among urban trees growing in metropolitan Lexington, Kentucky. Castanea, 44(2), 94-98.

Carpenter, S. B., \& Smith, N. D. (1981). A comparative study of leaf thickness among southern Appalachian hardwoods. Canadian Journal of Botany, 59(8), 1393-1396.

Dongsheng, L., Manxi, H., Huijuan, W., \& Ziqian, W. (2007). Law of fluctuation in plant leaves thickness during day and night. Journal of Physics: Conference Series, 48, 1447-1452.

Eames, A. J., \& MacDaniels, L. H. (1925). An introduction to plant anatomy (1st ed.). New York, NY: McGraw-Hill.

Gall, H., Philippe, F., Domon, J.-M., Gillet, F., Pelloux, J., \& Rayon, C. (2015). Cell wall metabolism in response to abiotic stress. Plants, 4(1), 112-166.

Gausman, H. (1974). Leaf reflectance of near-infrared. Photogrammetric Engineering, 40, 183191.

Gausman, H. W., Allen, W. A., Cardenas, R., \& Richardson, A. J. (1970). Relation of light reflectance to histological and physical evaluations of cotton leaf maturity. Applied Optics, 9(3), 545-552.

Giuliani, R., Koteyeva, N., Voznesenskaya, E., Evans, M. A., Cousins, A. B., \& Edwards, G. E. (2013). Coordination of leaf photosynthesis, transpiration, and structural traits in rice and wild relatives (Genus Oryza). Plant Physiology, 162(3), 1632-51.

Hanba, Y. T., Miyazawa, S. I., \& Terashima, I. (1999). The influence of leaf thickness on the $\mathrm{CO}_{2}$ transfer conductance and leaf stable carbon isotope ratio for some evergreen tree species in Japanese warm-temperate forests. Functional Ecology, 13(5), 632-639. doi:10.1046/j.1365-2435.1999.00364.x

Hoffman, G. J., Rhoades, J. D., Letey, F., \& Sheng, J. (1990). Salinity management. In G. J. Hoffman, T. A. Howell, \& K. H. Solomon (Eds.), Management of farm irrigation systems (pp. 667-715). St. Joseph, MI: American Society of Agricultural Engineers.

Jones, H. G. (2004). Irrigation scheduling: advantages and pitfalls of plant-based methods. Journal of Experimental Botany, 55(407), 2427-36. 
Jones, H. G. (2007). Monitoring plant and soil water status: Established and novel methods revisited and their relevance to studies of drought tolerance. Journal of Experimental Botany, 58(2), 119-130. http://doi.org/10.1093/jxb/erl118

Jones, H. G. (2014). Plants and microclimate: a quantitative approach to environmental plant physiology (3rd ed.). Cambridge: Cambridge University Press.

Kramer, P. J., \& Boyer, J. S. (1995). Water relations of plants and soils. San Diego: Academic Press.

Lambers, H., Chapin, F. S., \& Pons, T. L. (2008). Plant Physiological Ecology. New York: Springer New York.

Lenz, T. I., Wright, I. J., \& Westoby, M. (2006). Interrelations among pressure-volume curve traits across species and water availability gradients. Physiologia Plantarum, 127(3), 423433.

Li, D., \& Song, J. (2009). A novel irrigation system controlled by leaf thickness. In ASABE Annual International Meeting. Reno, Nevada: American Society of Agricultural and Biological Engineers (ASABE).

Maas, E. V., \& Hoffman, G. J. (1977). Crop salt tolerance: current assessment. Journal of Irrigation and Drainage Division, American Society of Civil Engineers, 103(2), 115-134.

Malone, M. (1993). Rapid inhibition of leaf growth by root cooling in wheat: kinetics and mechanism. Journal of Experimental Botany, 44(268), 1663-1669.

Marenco, R. A., Antezana-Vera, S. A., \& Nascimento, H. C. S. (2009). Relationship between specific leaf area, leaf thickness, leaf water content and SPAD-502 readings in six Amazonian tree species. Photosynthetica, 47(2), 184-190.

Martinez, J. P., Silva, H., Ledent, J. F., \& Pinto, M. (2007). Effect of drought stress on the osmotic adjustment, cell wall elasticity and cell volume of six cultivars of common beans (Phaseolus vulgaris L.). European Journal of Agronomy, 26(1), 30-38.

McBurney, T. (1992). The relationship between leaf thickness and plant water potential. Journal of Experimental Botany, 43(248), 327-335.

Meidner, H. (1952). An instrument for the continuous determination of leaf thickness changes in the field. Journal of Experimental Botany, 3(9), 319-325.

Morgan, J. a. (1986). The effects of $\mathrm{N}$ nutrition on the water relations and gas exchange characteristics of wheat (Triticum aestivum L.). Plant Physiology, 80(1), 52-58. 
Multari, S., Stewart, D., \& Russell, W. R. (2015). Potential of fava bean as future protein supply to partially replace meat intake in the human diet. Comprehensive Reviews in Food Science and Food Safety, 14, 511-522.

Myburg, A. A., \& Sederoff, R. R. (2001). Xylem structure and function. In Encyclopedia of Life Sciences. Nature Publishing Group. doi:10.1038/npg.els.0001302

Neumann, H. H., Thurtell, G. W., Stevenson, K. R., \& Beadle, C. L. (1974). Leaf water content and potential in corn, sorghum, soybean, and sunflower. Canadian Journal of Plant Science, 54(1), 185-195.

Nicotra, A. B., Leigh, A., Boyce, C. K., Jones, C. S., Niklas, K. J., Royer, D. L., \& Tsukaya, H. (2011). The evolution and functional significance of leaf shape in the angiosperms. Functional Plant Biology, 38, 535-552.

Nobel, P. S. (2009). Physicochemical and environmental plant physiology (4th ed). San Diego: Academic Press.

Nobel, P. S., \& Hartsock, T. L. (1981). Development of leaf thickness for Plectranthus parviflorus - influence of photosynthetically active radiation. Physiologia Plantarum, 51(2), 163-166.

Parida, A. K., \& Das, A. B. (2005). Salt tolerance and salinity effects on plants: a review. Ecotoxicology and Environmental Safety, 60(3), 324-349.

Parida, A. K., Das, A. B., \& Mittra, B. (2004). Effects of salt on growth, ion accumulation, photosynthesis and leaf anatomy of the mangrove, Bruguiera parviflora. Trees - Structure and Function, 18(2), 167-174.

Patakas, A., \& Noitsakis, B. (1997). Cell wall elasticity as a mechanism to maintain favorable water relations during leaf ontogeny in grapevines. American Journal of Enology and Viticulture, 48(3), 352-356.

Peng, S., \& Ismail, A. M. (2004). Physiology basis of yield and environmental adaptation in rice. In H. T. Nguyen \& A. Blum (Eds.), Physiology and biotechnology integration for plant breeding (pp. 72-118). New York: Marcel Dekker.

Read, J., \& Stokes, A. (2006). Plant biomechanics in an ecological context. American Journal of Botany, 93(10), 1546-1565.

Rhizopoulou, S., \& Psaras, G. K. (2003). Development and structure of drought-tolerant leaves of the Mediterranean shrub Capparis spinosa L. Annals of Botany, 92(3), 377-383. 
Rozema, J., Arp, W., Diggelen, J., Kok, E., \& Letschert, J. (1987). An ecophysiological comparison of measurements of the diurnal rhythm of the leaf elongation and changes of the leaf thickness of salt-resistant dicotyledonae and monocotyledonae. Journal of Experimental Botany, 38(188), 442-453.

Ryan, S. E., \& Porth, L. S. (2007). A tutorial on the piecewise regression approach applied to bedload transport data. General technical report RMRS-GTR-189. General Technical Report RMRS-GTR-189. Fort Collins, Colorado: U.S. Department of Agriculture, Forest Service, Rocky Mountain Research Station. Retrieved on July 12, 2016, from http://www.fs.fed.us/rm/pubs/rmrs_gtr189.pdf

Sabadin, P. K., Malosetti, M., Boer, M. P., Tardin, F. D., Santos, F. G., Guimarães, C. T., ... Magalhaes, J. V. (2012). Studying the genetic basis of drought tolerance in sorghum by managed stress trials and adjustments for phenological and plant height differences. Theoretical and Applied Genetics, 124(8), 1389-1402.

Sack, L., \& Scoffoni, C. (2012). Measurement of leaf hydraulic conductance and stomatal conductance and their responses to irradiance and dehydration using the Evaporative Flux Method (EFM). Journal of Visualized Experiments, 70(e4179). doi:10.3791/4179

Sack, L., \& Scoffoni, C. (2013). Leaf venation: structure, function, development, evolution, ecology and applications in the past, present and future. New Phytologist, 198(4), 9831000.

Sanchez-Diaz, M. F., \& Kramer, P. J. (1971). Behavior of corn and sorghum under water stress and during recovery. Plant Physiology, 48(5), 613-616.

Sancho-Knapik, D., Alvarez-Arenas, T. G., Peguero-Pina, J. J., Fernández, V., \& Gil-Pelegrín, E. (2011). Relationship between ultrasonic properties and structural changes in the mesophyll during leaf dehydration. Journal of Experimental Botany, 62(10), 3637-45.

Scoffoni, C., Vuong, C., Diep, S., Cochard, H., \& Sack, L. (2014). Leaf shrinkage with dehydration: coordination with hydraulic vulnerability and drought tolerance. Plant Physiology, 164(4), 1772-1788.

Seelig, H. D., Stoner, R. J., \& Linden, J. C. (2011). Irrigation control of cowpea plants using the measurement of leaf thickness under greenhouse conditions. Irrigation Science, 30(4), $247-$ 257. 
Seelig, H. D., Wolter, A., \& Schröder, F. G. (2015). Leaf thickness and turgor pressure in bean during plant desiccation. Scientia Horticulturae, 184, 55-62. http://doi.org/10.1016/j.scienta.2014.12.025

Sharon, Y., \& Bravdo, B. (1996). Irrigation control of citrus according to the diurnal cycling of leaf thickness. In Conference on Water \& Irrigation, Tel Aviv, Israel (pp. 273-283).

Smith, W. K., Bell, D. T., \& Shepherd, K. A. (1998). Associations between leaf structure, orientation, and sunlight exposure in five western Australian communities. American Journal of Botany, 85(1), 56-63.

Stoyanov, Z. (2005). Effects of water stress on leaf water relations of young bean plants. Central European Agriculture, 6(1), 5-14.

Sylvester, A. (2001). Leaf shape and anatomy as indicators of phase change in the grasses: comparison of maize, rice, and bluegrass. American Journal of Botany, 88(12), 2157-2167.

Syvertsen, J., \& Levy, Y. (1982). Diurnal changes in citrus leaf thickness, leaf water potential and leaf to air temperature difference. Journal of Experimental Botany, 33(135), 783-789.

Taiz, L., \& Zeiger, E. (2006). Plant Physiology (4th ed.). Sunderland, MA: Sinauer Associates. Takai, T., Adachi, S., Taguchi-Shiobara, F., Sanoh-Arai, Y., Iwasawa, N., Yoshinaga, S., ... Yamamoto, T. (2013). A natural variant of NAL1, selected in high-yield rice breeding programs, pleiotropically increases photosynthesis rate. Scientific Reports, 3, 2149.

Vile, D., Garnier, E., Shipley, B., Laurent, G., Navas, M.-L., Roumet, C., ... Wright, I. J. (2005). Specific leaf area and dry matter content estimate thickness in laminar leaves. Annals of Botany, 96(6), 1129-36.

Vogelmann, T. C., Bornman, J. F., \& Yates, D. J. (1996). Focusing of light by leaf epidermal cells. Physiologia Plantarum, 98(1), 43-56.

White, J. W., \& Montes-R, C. (2005). Variation in parameters related to leaf thickness in common bean (Phaseolus vulgaris L.). Field Crops Research, 91(1), 7-21.

Yun, J. I., \& Taylor, S. E. (1986). Adaptive implications of leaf thickness for sun- and shadegrown Abutilon theophrasti. Ecology, 67(5), 1314-1318.

Zagorchev, L., Kamenova, P., \& Odjakova, M. (2014). The role of plant cell wall proteins in response to salt stress. The Scientific World Journal, 2014. 


\section{Tables}

Table 1 - Estimated parameters for the piecewise regression models of leaf relative water content (RWC) vs. leaf relative thickness (RT) for different species. $c$ is the RT at the breakpoint of the piecewise model, $b_{1}$ and $b_{2}$ are the slopes of the model for respectively RT $>c$ and RT $\leq c$, and $a$ is the model intercept for $\mathrm{RT} \leq c$.

\begin{tabular}{llllllll}
\hline Species & $\boldsymbol{b}_{\boldsymbol{1}}$ & $\boldsymbol{c}$ & $\boldsymbol{b}_{\boldsymbol{2}}$ & $\boldsymbol{a}$ & $\mathbf{R}^{\mathbf{2}}$ & P-value & $\begin{array}{l}\text { Estimated } \\
\text { RWC at } \boldsymbol{c}\end{array}$ \\
\hline Corn & 0.166 & 0.672 & 1.050 & 0.208 & 0.86 & $<0.001$ & $91 \%$ \\
& \pm 0.113 & \pm 0.024 & \pm 0.051 & \pm 0.025 & & & \\
Sorghum & 0.348 & 0.750 & 1.156 & 0.032 & 0.97 & $<0.001$ & $90 \%$ \\
& \pm 0.075 & \pm 0.013 & \pm 0.032 & \pm 0.020 & & & \\
Soybean & 0.322 & 0.653 & 0.935 & 0.247 & 0.93 & $<0.001$ & $86 \%$ \\
& \pm 0.063 & \pm 0.024 & \pm 0.044 & \pm 0.022 & & & \\
Fava bean & 0.192 & 0.517 & 0.885 & 0.407 & 0.89 & $<0.001$ & $86 \%$ \\
& \pm 0.064 & \pm 0.029 & \pm 0.063 & \pm 0.021 & & & \\
\hline
\end{tabular}

Note: The margins of error are calculated based on a 95\% confidence interval. 
Table 2. Estimated parameters for the piecewise regression models of leaf relative water content (RWC) vs. leaf relative thickness (RT) across leaf locations of the species. $c$ is the RT at the breakpoint of the piecewise model, $b_{1}$ and $b_{2}$ are the slopes of the model for respectively RT $>c$ and RT $\leq c$, and $a$ is the model intercept for $\mathrm{RT} \leq c$.

\begin{tabular}{|c|c|c|c|c|c|c|c|c|}
\hline Species & $\begin{array}{l}\text { Leaf } \\
\text { location }\end{array}$ & $b_{1}$ & $c$ & $b_{2}$ & $a$ & $\mathbf{R}^{2}$ & P-value & $\begin{array}{l}\text { Estimated } \\
\text { RWC at } c\end{array}$ \\
\hline \multirow[t]{3}{*}{ Corn } & Top & $\begin{array}{l}0.229 \\
\pm 0.150\end{array}$ & $\begin{array}{l}0.557 \\
\pm 0.025\end{array}$ & $\begin{array}{l}1.435 \\
\pm 0.107\end{array}$ & $\begin{array}{l}0.070 \\
\pm 0.056\end{array}$ & 0.99 & $<0.001$ & $87 \%$ \\
\hline & Middle & $\begin{array}{l}0.169 \\
\pm 0.036\end{array}$ & $\begin{array}{l}0.635 \\
\pm 0.007\end{array}$ & $\begin{array}{l}1.220 \\
\pm 0.021\end{array}$ & $\begin{array}{l}0.142 \\
\pm 0.010\end{array}$ & 0.99 & $<0.001$ & $92 \%$ \\
\hline & Bottom & $\begin{array}{l}0.223 \\
\pm 0.022\end{array}$ & $\begin{array}{l}0.662 \\
\pm 0.005\end{array}$ & $\begin{array}{l}1.334 \\
\pm 0.029\end{array}$ & $\begin{array}{l}0.015 \\
\pm 0.013\end{array}$ & 0.90 & $<0.001$ & $90 \%$ \\
\hline \multirow[t]{3}{*}{ Sorghum } & Top & $\begin{array}{l}0.452 \\
\pm 0.059\end{array}$ & $\begin{array}{l}0.694 \\
\pm 0.007\end{array}$ & $\begin{array}{l}1.115 \\
\pm 0.021\end{array}$ & $\begin{array}{l}0.075 \\
\pm 0.013\end{array}$ & $>0.99$ & $<0.001$ & $85 \%$ \\
\hline & Middle & $\begin{array}{l}0.380 \\
\pm 0.036\end{array}$ & $\begin{array}{l}0.728 \\
\pm 0.006\end{array}$ & $\begin{array}{l}1.247 \\
\pm 0.020\end{array}$ & $\begin{array}{l}-0.020 \\
\pm 0.012\end{array}$ & $>0.99$ & $<0.001$ & $89 \%$ \\
\hline & Bottom & $\begin{array}{l}0.276 \\
\pm 0.022\end{array}$ & $\begin{array}{l}0.766 \\
\pm 0.007\end{array}$ & $\begin{array}{l}1.353 \\
\pm 0.018\end{array}$ & $\begin{array}{l}-0.110 \\
\pm 0.010\end{array}$ & $>0.99$ & $<0.001$ & $93 \%$ \\
\hline \multirow[t]{3}{*}{ Soybean } & Top & $\begin{array}{l}0.289 \\
\pm 0.045\end{array}$ & $\begin{array}{l}0.650 \\
\pm 0.016\end{array}$ & $\begin{array}{l}0.976 \\
\pm 0.066\end{array}$ & $\begin{array}{l}0.248 \\
\pm 0.033\end{array}$ & 0.98 & $<0.001$ & $88 \%$ \\
\hline & Middle & $\begin{array}{l}0.282 \\
\pm 0.025\end{array}$ & $\begin{array}{l}0.637 \\
\pm 0.008\end{array}$ & $\begin{array}{l}1.038 \\
\pm 0.021\end{array}$ & $\begin{array}{l}0.209 \\
\pm 0.010\end{array}$ & $>0.99$ & $<0.001$ & $87 \%$ \\
\hline & Bottom & $\begin{array}{l}0.379 \\
\pm 0.049\end{array}$ & $\begin{array}{l}0.611 \\
\pm 0.017\end{array}$ & $\begin{array}{l}1.118 \\
\pm 0.033\end{array}$ & $\begin{array}{l}0.116 \\
\pm 0.016\end{array}$ & 0.98 & $<0.001$ & $80 \%$ \\
\hline \multirow[t]{3}{*}{ Fava bean } & Top & $\begin{array}{l}0.239 \\
\pm 0.022\end{array}$ & $\begin{array}{l}0.487 \\
\pm 0.011\end{array}$ & $\begin{array}{l}1.236 \\
\pm 0.056\end{array}$ & $\begin{array}{l}0.242 \\
\pm 0.016\end{array}$ & 0.91 & $<0.001$ & $84 \%$ \\
\hline & Middle & $\begin{array}{l}0.211 \\
\pm 0.042\end{array}$ & $\begin{array}{l}0.425 \\
\pm 0.013\end{array}$ & $\begin{array}{l}1.314 \\
\pm 0.078\end{array}$ & $\begin{array}{l}0.289 \\
\pm 0.024\end{array}$ & 0.97 & $<0.001$ & $85 \%$ \\
\hline & Bottom & $\begin{array}{l}0.257 \\
\pm 0.082\end{array}$ & $\begin{array}{l}0.394 \\
\pm 0.031\end{array}$ & $\begin{array}{l}1.100 \\
\pm 0.166\end{array}$ & $\begin{array}{l}0.374 \\
\pm 0.061\end{array}$ & 0.99 & $<0.001$ & $81 \%$ \\
\hline
\end{tabular}

Note: The margins of error are calculated based on a $95 \%$ confidence interval. 
Table 3. The significance of leaf location as a factor in the variability of the piecewise model parameters of leaf relative water content vs. leaf relative thickness (RT). $c$ is the RT at the breakpoint of the piecewise model, $b_{1}$ and $b_{2}$ are the slopes of the model for respectively RT $>c$ and RT $\leq c$, and $a$ is the model intercept for $\mathrm{RT} \leq c$.

\begin{tabular}{|c|c|c|c|c|}
\hline \multirow[b]{2}{*}{ Species } & \multicolumn{4}{|c|}{ P-value } \\
\hline & $b_{1}$ & $c$ & $b_{2}$ & $a$ \\
\hline Corn & $<0.01$ & 0.01 & 0.51 & 0.66 \\
\hline Sorghum & $<0.01$ & 0.01 & 0.20 & 0.21 \\
\hline Soybean & 0.04 & 0.80 & $<0.01$ & $<0.01$ \\
\hline Fava bean & 0.01 & 0.49 & $<0.01$ & 0.01 \\
\hline
\end{tabular}




\section{Figure captions}

Fig. 1. Schematic of the thickness sensor.

Fig. 2. Fitted piecewise models of leaf relative water content (RWC) vs. leaf relative thickness (RT) for corn (A), sorghum (B), soybean (C), and fava bean (D). The solid lines show the piecewise regression lines. The grey points display the observations.

Fig. 3. The relationship between linear piecewise model parameters of leaf relative water content-relative thickness (RT) with soil electrical conductivity (EC) threshold (maximum EC that does not result in yield loss) for corn $(\boldsymbol{\Delta})$, sorghum $(\boldsymbol{\square})$, soybean $(0)$, and fava bean $(\bullet) . c$ is the RT at the breakpoint of the piecewise model, and $b_{1}$ and $b_{2}$ are the slopes of the model for respectively $\mathrm{RT}>c$ and $\mathrm{RT} \leq c$. A) $b_{1}$ vs. threshold $\left(\mathrm{y}=0.035 \mathrm{x}+0.126 ; \mathrm{R}^{2}=0.95 ; \mathrm{p}\right.$-value $=$ $0.02), \mathrm{B}) c$ vs. threshold $\left(\mathrm{y}=0.028 \mathrm{x}+0.542 ; \mathrm{R}^{2}=0.54\right.$; $\mathrm{p}$-value $\left.\left.=0.26\right), \mathrm{C}\right) b_{2}$ vs. threshold $(\mathrm{y}=$ $0.027 \mathrm{x}+0.903 ; \mathrm{R}^{2}=0.33 ; \mathrm{p}$-value $=0.42$ ). The references for the EC threshold data of the crops are cited in the text. 
Figures

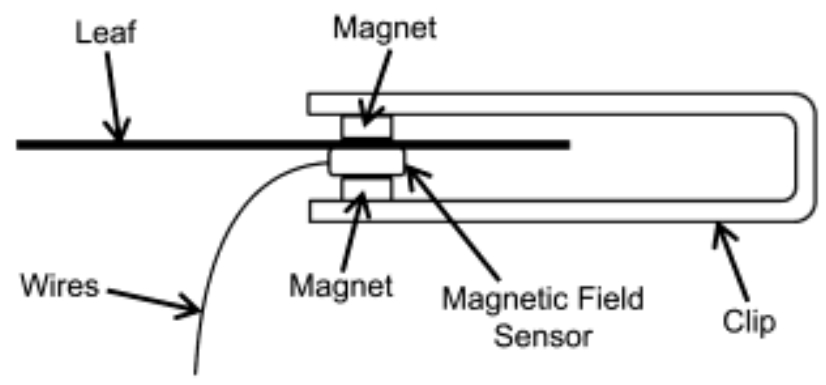

Fig. 1. Schematic of the thickness sensor. 

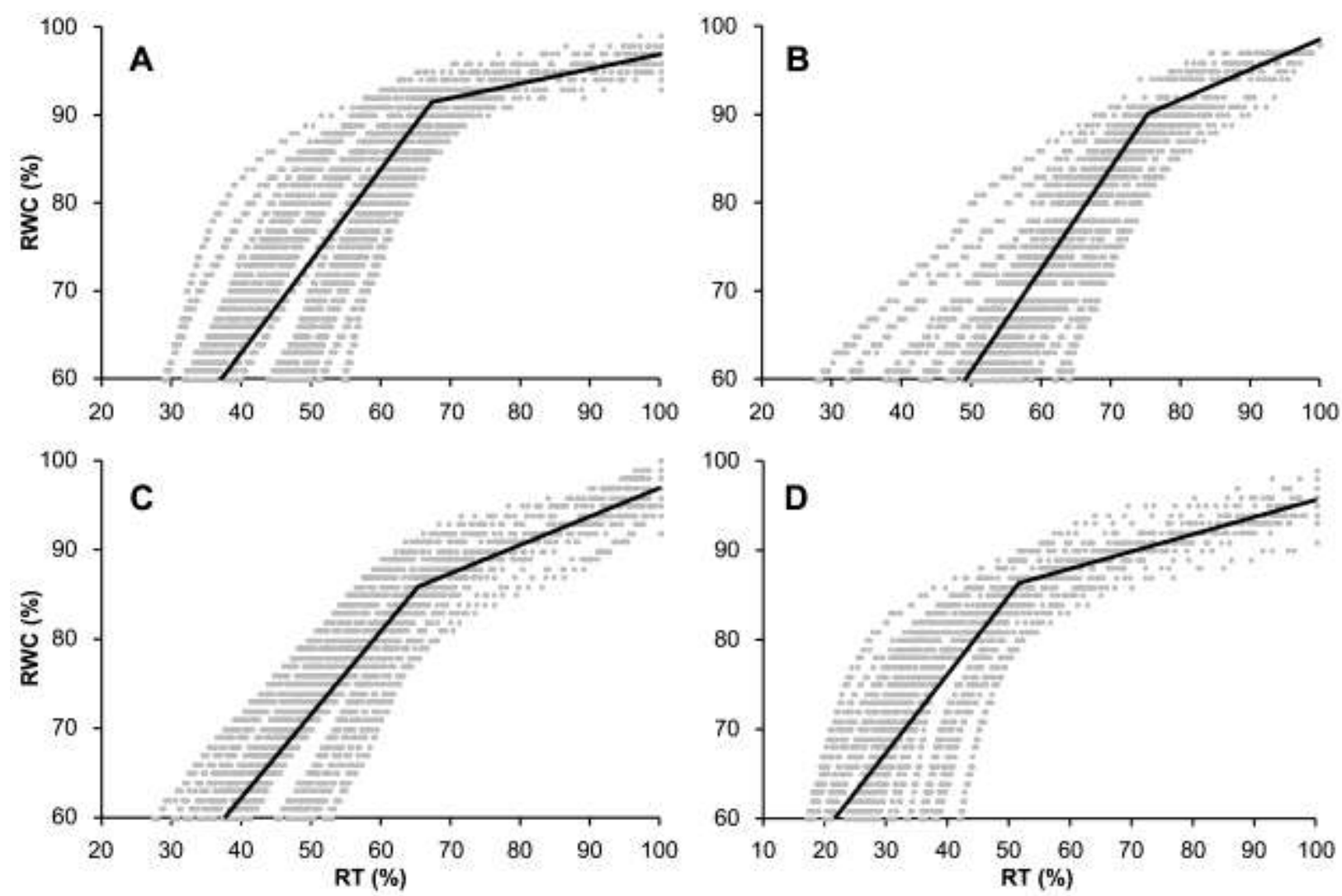

Fig. 2. Fitted piecewise models of leaf relative water content (RWC) vs. leaf relative thickness (RT) for corn (A), sorghum (B), soybean (C), and fava bean (D). The solid lines show the piecewise regression lines. The grey points display the observations. 

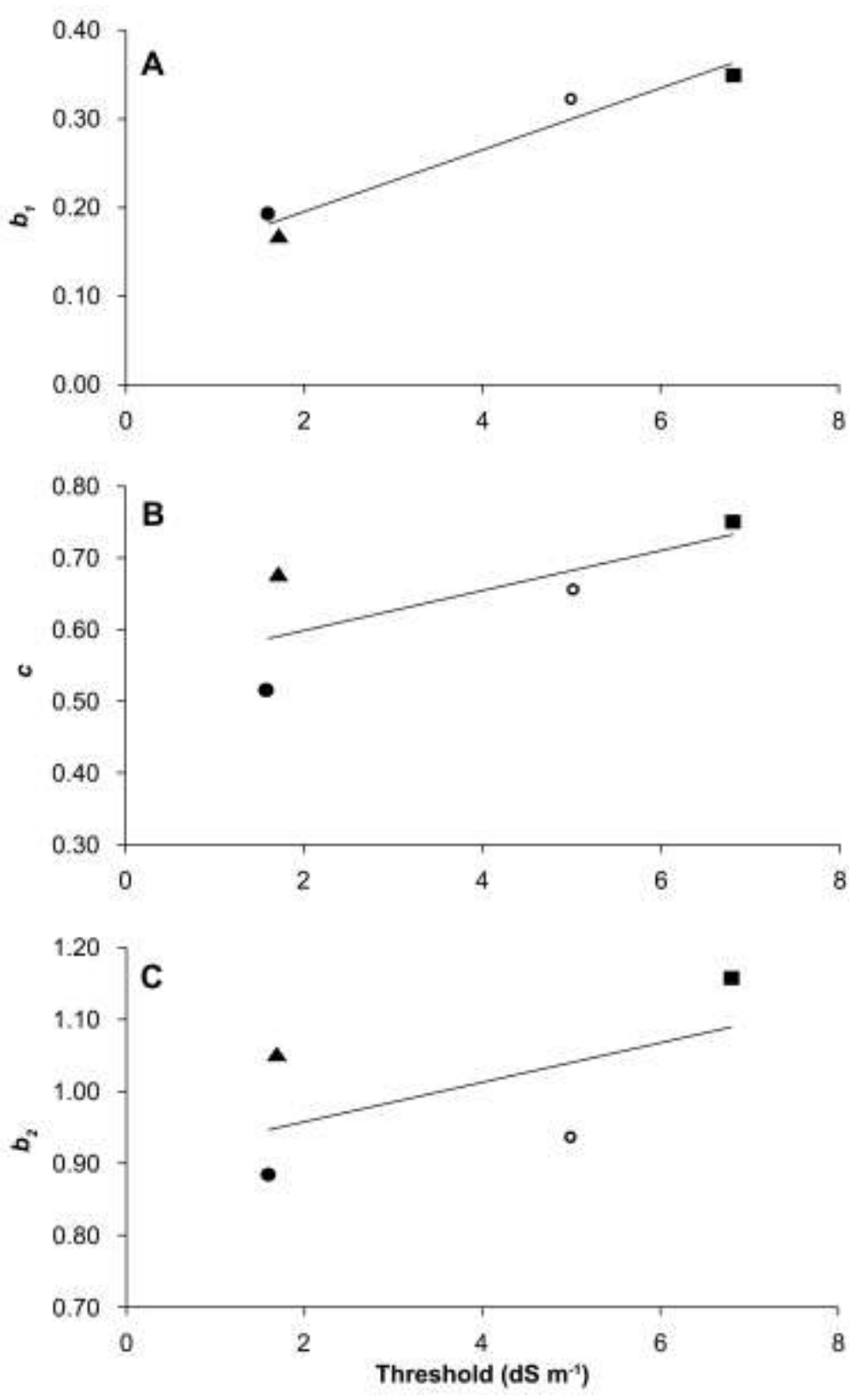

Fig. 3. The relationship between linear piecewise model parameters of leaf relative water content-relative thickness (RT) with soil electrical conductivity (EC) threshold (maximum EC that does not result in yield loss) for corn ( $\boldsymbol{\Delta})$, sorghum $(\boldsymbol{\square})$, soybean $(\circ)$, and fava bean $(\bullet) . c$ is the RT at the breakpoint of the piecewise model, and $b_{1}$ and $b_{2}$ are the slopes of the model for respectively $\mathrm{RT}>c$ and $\mathrm{RT} \leq c$. A) $b_{1}$ vs. threshold $\left(\mathrm{y}=0.035 \mathrm{x}+0.126 ; \mathrm{R}^{2}=0.95 ; \mathrm{p}-\right.$ value $=0.02), \mathrm{B}) c$ vs. threshold $(\mathrm{y}=0.028 \mathrm{x}$ $+0.542 ; \mathrm{R}^{2}=0.54 ; \mathrm{p}$-value $\left.\left.=0.26\right), \mathrm{C}\right) b_{2}$ vs. threshold $\left(\mathrm{y}=0.027 \mathrm{x}+0.903 ; \mathrm{R}^{2}=\right.$ 0.33 ; $\mathrm{p}$-value $=0.42)$. The references for the EC threshold data of the crops are cited in the text. 